\title{
Preservation of Arctic dinosaur remains from the Prince Creek Formation (Alaska, USA): A reply to Fiorillo (2016)
}

\author{
HIROTSUGU MORI, PATRICK S. DRUCKENMILLER, and GREGORY M. ERICKSON
}

We thank Anthony Fiorillo (2016) for the concerns he raised regarding our characterizations of the Liscomb bonebed fossils in our paper describing Ugrunaaluk kuukpikenis from the Prince Creek Formation of Alaska, USA (Mori et al. 2016). We did not imply that the bones are not "fossilized". The bones are from animals that lived in the geologic past ( $\sim 70$ million years old) and are therefore fossils by definition. In our generalized description of bone preservation, we used the modifier "typically" in describing the degree to which bones are uncrushed and permineralized. We did not contend that bones are never uncrushed or permineralized. We recognize that the bones are ferruginous in color reflecting some degree of iron-bearing mineral infiltration, which technically can be categorized as permineralized. However, vertebrate paleontologists typically reserve this term for cases where mineral infiltration lines the vascular canals and trabecular spaces of bones and is visible macroscopically. We are aware that some bones in the Liscomb Bonebed exhibit this type of preservation, but maintain that it occurs in a surprisingly small, currently unquantified percentage of bones. We apologize for any confusion this may have caused. Finally, in supporting our general diagenetic comments about the Liscomb Bonebed, we cited the comprehensive works by Gangloff and Fiorillo (2010) and Fiorillo et al. (2010) — the two most relevant works on the subject. These would have been glaring omissions had we not done so.

\section{References}

Fiorillo, A.R. 2016. Comment on "A new Arctic hadrosaurid from the Prince Creek Formation (lower Maastrichtian) of northern Alaska" by Hirotsugu Mori, Patrick S. Druckenmiller, and Gregory M. Erickson. Acta Palaeontologica Polonica 61: 158.

Fiorillo, A.R., McCarthy, P.J., and Flaig, P.P. 2010. Taphonomic and sedimentologic interpretations of the dinosaur-bearing Upper Cretaceous strata of the Prince Creek Formation, Northern Alaska: insights into an ancient high-latitude terrestrial ecosystem. Palaeogeography, Palaeoclimatology, Palaeoecology 295: 376-388.

Gangloff, R.A. and Fiorillo, A.R. 2010. Taphonomy and paleoecology of a bonebed from the Prince Creek Formation, North Slope, Alaska. Palaios 25: 299-317.

Mori, H., Druckenmiller, P.S., and Erickson, G.M. 2016. A new Arctic hadrosaurid from the Prince Creek Formation (lower Maastrichtian) of northern Alaska. Acta Palaeontologica Polonica 61: 15-132.

Hirotsugu Mori [hmori@alaska.edu], Department of Geosciences, University of Alaska Fairbanks, 900 Yukon Drive, Fairbanks, AK 99775-5780, USA; University of Alaska Museum, 907 Yukon Drive, Fairbanks, AK 99775, USA; and Saikai City Board of Education; Setoitanoura Go, Oseto Cho, Saikai City, Nagasaki Prefecture, 857-2301, Japan.

Patrick S. Druckenmiller [psdruckenmiller@alaska.edu], University of Alaska Museum, 907 Yukon Drive, Fairbanks, AK 99775, USA; and Department of Geosciences, University of Alaska Fairbanks, 900 Yukon Drive, Fairbanks, AK 99775-5780, USA.

Gregory M. Erickson [gerickson@bio.fsu.edu], Department of Biological Science, Florida State University, 319 Stadium Drive, Tallahassee, FL 323064295, USA.

Received 11 December 2015, accepted 12 December 2015, available online 19 January 2016.

Copyright (c) 2016 H. Mori et al. This is an open-access article distributed under the terms of the Creative Commons Attribution License (for details please see http://creativecommons.org/licenses/by/4.0/), which permits unrestricted use, distribution, and reproduction in any medium, provided the original author and source are credited. 